Macedonian Pharmaceutical Bulletin, 66 (Suppl 1) 31 - 32 (2020)

Online ISSN 1857 - 8969

UDC: $616.379-008.64-083.2$

DOI: 10.33320/maced.pharm.bull.2020.66.03.015

Short communication

\title{
Dietetic approach in patient with type 2 diabetes mellitus - a case report
}

\author{
Bojana Janeku*, Dafina Boshkoska, Elena Karabeleski, Menka Andreska, Suzana \\ Atanasoviкj, Dragana Mladenovska, Kristina Mladenovska, Lidija Petrushevska-Tozi, \\ Tanja Petreska Ivanovska, Aleksandra Kapedanovska Nestorovska
}

Faculty of Pharmacy, Ss. Cyril and Methodius University, Mother Theresa 47, 1000 Skopje, N. Macedonia

\section{Introduction}

The dietetics as a discipline and the dietitians as health professionals integrate principles of the health, biological, physiological, behavioral, social and food and nutrition sciences with management and communication to provide and maintain optimal human health within flexible scope of practice. The main activities include adequate screening/ assessment of patients' needs for nutritional therapy (NT), detecting the presence or risks for developing a nutrition-related problem, development of nutritional diagnosis, nutrition intervention and monitoring and evaluation of the nutrition care plan. Within that, a diabetes dietitian can offer specialist evidence-based dietary advice to patients with diabetes while considering factors including nutritional status, medication, diabetes control and lifestyle (Evert et al., 2019; Roth, 2010).

Type 2 diabetes mellitus (T2DM) is a chronic, metabolic disease with insulin resistant body cells. Risk for developing ketoacidosis is low, but elevated levels of blood glucose lead, over time, to serious damage to many systems. Although T2DM may experience marked hyperglycemia, many patients do not require insulin injections and diabetes can be controlled with pharmacotherapy (PT) i.e. oral hypoglycemic agents and proper lifestyle that includes a
diet/NT and regular physical activity. In this paper, a patient case is presented to show that the synergistic effect of PT and NT helps in control of T2DM and reducing co-morbidities. Also, the role of dietitian in providing the best diabetes control possible through a good understanding of the condition and the best use of medications is emphasized.

\section{Case presentation}

A 55-years old female patient (33.2 BMI) with a (family history of) T2DM diagnosed 30 years ago was hospitalized for foot ulcer, which was edematous, necrotic, with exudates and hot. Patient's medical history included hypertension and lipid profile that promoted cardiovascular complications. Microalbuminuria and disorders in electrolyte status indicated nephropathy and chronic kidney disease (CKD) in development. Symmetric distal peripheral neuropathy was also evidenced. In addition, menopausal symptoms and changes were experienced (e.g., weight gain) for which hormone replacement therapy and vitamins and minerals were prescribed. The patient had a poor lifestyle (pastarich diet, cigarettes and alcohol consumption and no physical activity). Laboratory tests showed increased values of following parameters: glucose $178 \mathrm{mg} / \mathrm{dL}$, HbA1C 8.9\%, HDL-C 48 mg/dL, triglycerides 180 $\mathrm{mg} / \mathrm{dL}$, creatinine $2.5 \mathrm{mg} / \mathrm{dL}$, blood urea nitrogen 37

*bojana.srbljak@gmail.com 
$\mathrm{mg} / \mathrm{dL}$, potassium $6.1 \mathrm{mg} / \mathrm{dL}$, microalbumin $45 \mathrm{mg}$. In addition to regular therapy (metformin á $500 \mathrm{mg}$, twice a day and amiloride hydrochloride á 5 mg/hydrochlorothiazide á $100 \mathrm{mg}$, propranolol á 80 $\mathrm{mg}$ (prolonged release) and atorvastatin á $10 \mathrm{mg}$ per day), amoxicillin/clavulanate $1000 \mathrm{mg}$ twice a day was administered for treatment of diabetic foot ulcer.

\section{Discussion}

T2DM is a complex disorder that is heterogeneous in nature, so NT plan should be implemented by prioritizing metabolic problems. In T2DM patients receiving PT, energy needs are calculated individually based on the glycemic index. The most acceptable method of NT is to count carbohydrate units in each meal.

Nutritional assessment of the patient, according to the BMI and the information on the significant increase of the body weight over the past period, pointed to obesity class 1 . Mayor problems in NT were allocated in poorly controlled T2DM that correlated with inappropriate lifestyle and insufficient awareness of self-control and contributed to development of long-term cardiovascular and nephrological complications. With nutritional diagnosis, inadequate ratio of major nutrition components and low intake of dietary fibers was detected. In addition, potential interactions between alcohol consumption and metformin were identified as a risk for developing lactic acidosis. Therefore, nutritional intervention was focused on changing nutritional habits, controlling and maintaining a balanced diet and mandatory lifestyle changes in terms of physical activity and cessation of alcohol and cigarette consumption. The priority was to achieve optimal glycemic control (by reducing $\mathrm{HbA} 1 \mathrm{C}$ for $1-2 \%$ ), control of lipid status (by reducing blood pressure and preventing further cardiovascular deterioration) and consequently, to control the nephropathy and peripheral vascular disease (hygiene treatment and exercise), all through joint venture of PT and NT. Extra goal was to reduce body mass by $10-15 \%$ and to improve insulin sensitivity. According to the total energy expenditure calculation, the patient received energy intake of up to $2000 \mathrm{kcal} / \mathrm{day}$, with the distribution of macro-nutrients according to her diagnosis as follows: 50-60\% carbohydrates (with a low glycemic index); up to $10 \%$ protein; up to $30 \%$ fat. Since the patient was on a normal diet (no need for liquid food), the design of meals included up to $1200 \mathrm{kcal}$ from carbohydrates $(60-75 \mathrm{~g}$ in main meals, max. 200-225 g/day), up to $200 \mathrm{kcal}$ from protein, and up to $600 \mathrm{kcal}$ from fat. Since the patient had bad lifestyle and poor self-control, after the hospital stay, she was trained in proper food and nutrition management, better understanding of the complications and their management and was advised to perform regular controls. She was offered self-monitoring guidelines and an appropriate psychological support for managing the stress. In addition, she was educated for proper use of food and drugs in order to minimize the interactions. Since metformin reduces the absorption of vitamin $\mathrm{B}_{12}$ and folates and increases the risk of anemia, the diet rich in vitamin $\mathrm{B}$ was recommended. To avoid potassium rich food was also recommended because of potassium-spearing diuretic in therapy. Despite debridement and therapy of leg ulcer, it took 4 weeks to fully recover (with reduced calorie intake and extra PT). Physical activity was introduced afterwards, gradually, with suggested menus from 2000 to $2500 \mathrm{kcal}$ and mandatory glucose monitoring by scheme.

\section{Conclusion}

T2DM treatment comprising NT, PT and physical activity may provide adequate glycemic control. Complete control of diabetes requires awareness of the importance of each of the therapies, the synergistic relationship between them and the maximum adherence to each therapy, including nutrition interventions by the certified dietitian.

\section{References}

Roth, S.L., 2010. Diseases of the endocrine system, second ed., in: Cossio, Y. (Ed.), Nutrition Therapy \& Pathophysiology. Cengage Learning, Belmont, pp. 471-519.

Evert, A.B., Dennison, M., Gardner, C.D.W., Garvey, T., Lau, K.H.K., MacLeod, J., Mitri, J., Pereira, R.F., Rawlings, K., Robinson, S., Saslow, L., Uelmen, S., Urbanski, P.B., Yancy. W.S., 2019. Nutrition therapy for adults with diabetes or pre-diabetes: A consensus report. Diabetes Care 42(5), 731-754.

Maced. Pharm. Bull. 66 (Suppl 1) 31 - 32 (2020) 